\title{
NF-kB-responsive miR-155 induces functional impairment of vascular smooth muscle cells by downregulating soluble guanylyl cyclase
}

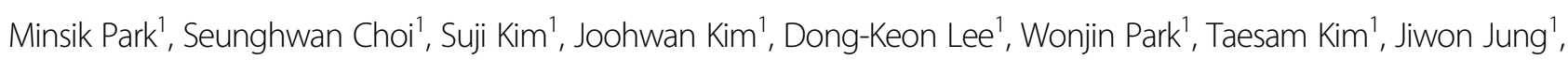
Jong Yun Hwang ${ }^{2}$, Moo-Ho Won $\mathbb{0}^{3}$, Sungwoo Ryoo ${ }^{4}$, Seung Goo Kang ${ }^{5}$, Kwon-Soo Ha ${ }^{1}$, Young-Guen Kwon ${ }^{6}$ and Young-Myeong Kim ${ }^{1}$

\begin{abstract}
Vascular smooth muscle cells (VSMCS) play an important role in maintaining vascular function. Inflammation-mediated VSMC dysfunction leads to atherosclerotic intimal hyperplasia and preeclamptic hypertension; however, the underlying mechanisms are not clearly understood. We analyzed the expression levels of microRNA-155 (miR-155) in cultured VSMCs, mouse vessels, and clinical specimens and then assessed its role in VSMC function. Treatment with tumor necrosis factor-a (TNF-a) elevated miR-155 biogenesis in cultured VSMCs and vessel segments, which was prevented by NF-KB inhibition. MiR-155 expression was also increased in high-fat diet-fed $\mathrm{ApoE}^{-/-}$mice and in patients with atherosclerosis and preeclampsia. The miR-155 levels were inversely correlated with soluble guanylyl cyclase $\beta 1$ (sGC $\beta 1$ ) expression and nitric oxide (NO)-dependent CGMP production through targeting the sGC 1 transcript. TNF-a-induced miR-155 caused VSMC phenotypic switching, which was confirmed by the downregulation of VSMC-specific marker genes, suppression of cell proliferation and migration, alterations in cell morphology, and NO-induced vasorelaxation. These events were mitigated by miR-155 inhibition. Moreover, TNF-a did not cause VSMC phenotypic modulation and limit NO-induced vasodilation in

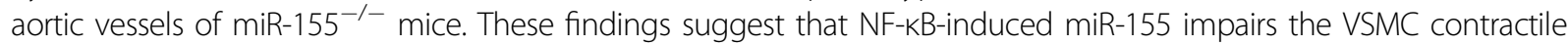
phenotype and NO-mediated vasorelaxation by downregulating sGC 31 expression. These data suggest that NF-kBresponsive miR-155 is a novel negative regulator of VSMC functions by impairing the sGC/cGMP pathway, which is essential for maintaining the VSMC contractile phenotype and vasorelaxation, offering a new therapeutic target for the treatment of atherosclerosis and preeclampsia.
\end{abstract}

\section{Introduction}

The interaction and communication between endothelial cells and vascular smooth muscle cells (VSMCs) play crucial roles in regulating vascular function, such as vascular

Correspondence: Young-Myeong Kim (ymkim@kangwon.ac.kr) ${ }^{1}$ Departments of Molecular and Cellular Biochemistry, Kangwon National University School of Medicine, Chuncheon, Gangwon-do 24341, South Korea ${ }^{2}$ Departments of Obstetrics and Gynecology, Kangwon National University School of Medicine, Chuncheon, Gangwon-do 24341, South Korea Full list of author information is available at the end of the article. remodeling and relaxation, through the endothelial nitric oxide synthase (eNOS)-derived $\mathrm{NO} /$ soluble guanylyl cyclase (sGC) pathway ${ }^{1}$. In addition to endothelial dysfunction, phenotypic switching of VSMCs from a 'contractile' to a pathological 'synthetic' state has been shown to play an important role in the pathogenesis of atherosclerosis, as well as in a variety of other major human diseases, including hypertension and preeclampsia ${ }^{2,3}$.

Phenotypic modulation of VSMCs is accelerated by various environmental cues, such as inflammatory

\section{(c) The Author(s) 2019}

(c) (i) Open Access This article is licensed under a Creative Commons Attribution 4.0 International License, which permits use, sharing, adaptation, distribution and reproduction c. in any medium or format, as long as you give appropriate credit to the original author(s) and the source, provide a link to the Creative Commons license, and indicate if changes were made. The images or other third party material in this article are included in the article's Creative Commons license, unless indicated otherwise in a credit line to the material. If material is not included in the article's Creative Commons license and your intended use is not permitted by statutory regulation or exceeds the permitted use, you will need to obtain permission directly from the copyright holder. To view a copy of this license, visit http://creativecommons.org/licenses/by/4.0/. 
cytokines, growth factors, and vascular injury ${ }^{2}$. Additionally, endothelial NO inhibits the proliferation of VSMCs by sGC-dependent cGMP synthesis ${ }^{4}$, indicating that the eNOS/sGC pathway plays a critical role in neointimal proliferation and vascular relaxation during vascular inflammation and following arterial injury. Moreover, eNOS-deficient mice exhibit hypertension and show increased growth of the intima compared to their wild-type counterparts ${ }^{5,6}$. Moreover, sGC expression is downregulated in arterial vessels in spontaneous hypertensive rats ${ }^{7}$. These data suggest that the NO/cGMP pathway is important for VSMC phenotypic modulation and vasorelaxation. Although the expression of sGC is downregulated by inflammatory stimuli, such as TNF- $\alpha$ and IL-1 $\beta^{8}$, the association between sGC downregulation and VSMC dysfunction is poorly understood in inflammatory disease states.

MicroRNAs (miRNAs) are small non-coding RNAs that induce gene silencing through mRNA destabilization and translational repression by complementary binding to the $3^{\prime}$-untranslated region (3'-UTR) of target mRNAs ${ }^{9}$. Growing evidence has shown that several miRNAs are involved in endothelial and VSMC dysfunction, resulting in hypertension, neointimal growth, and vascular remodeling through targeting of specific genes ${ }^{10-13}$. Despite evidence that the sGC/cGMP pathway plays a crucial role in altering or modulating VSMC function, the underlying mechanism involving miRNAs in inflammatory vascular diseases, including atherosclerosis and preeclampsia, remains unclear.

NF-kB-responsive miRNA-155 (miR-155) has been implicated in endothelial dysfunction ${ }^{14,15}$, tumor progression $^{16}$, atherosclerosis ${ }^{13,17}$, and vascular inflammation and permeability ${ }^{18,19}$. However, little is known regarding the involvement of miR-155 in regulating VSMC function and phenotypic switching associated with hypertension and intimal hyperplasia. Here, we found that miR-155 is upregulated in patients with atherosclerosis and preeclampsia and facilitates phenotypic and functional alterations of VSMCs by inhibiting the activity of the sGC/cGMP axis by downregulating sGC $\beta 1$ expression, a subunit of dimeric sGC. These findings suggest that TNF$\alpha$-induced miR-155 expression is a molecular risk factor for atherosclerotic intima formation and preeclamptic hypertension via impairment of the sGC/cGMP pathway.

\section{Materials and Methods}

Please see the Supplementary Materials in the supplementary information.

\section{Clinical and animal samples}

Animal experiments were performed in accordance with the guidelines of the Institutional Animal Care and Use Ethics Committee of Kangwon National University
(KW-171228-1). Because both male and female C57BL/ $6 \mathrm{ApoE}^{-1-}$ mice are commonly used as animal models of atherosclerosis ${ }^{20}$, we used male C57BL/6 $\mathrm{ApoE}^{-1-}$ mice in this study. A total of 12 8-week-old male $\mathrm{ApoE}^{-1-}$ mice were randomly divided into two groups (6 in each) and fed either a normal chow diet or a highfat diet (HFD) containing $0.15 \%$ cholesterol and $20 \%$ fat for 16 weeks. After mice were sacrificed with $\mathrm{CO}_{2}$ gas, their aortas were promptly collected. Human tissue and blood samples were obtained from 11 healthy male adults and 11 male patients with atherosclerosis, as well as 10 healthy pregnant women and 10 patients with preeclampsia according to protocols approved by the Institutional Review Board at Kangwon National University Hospital (KNUH-2017-01-010-004), and informed consent was obtained from all participants. This investigation conformed to the principles outlined in the Declaration of Helsinki.

\section{Culture of VSMCs and endothelial cells}

Human aortic smooth muscle cells (HASMCs) were cultured in SMC medium containing 1\% penicillin/ streptomycin solution, $1 \%$ smooth muscle cell growth supplement and, $2 \%$ fetal bovine serum (FBS) at $37{ }^{\circ} \mathrm{C}$ in a humidified $\mathrm{CO}_{2}$ incubator with $5 \% \mathrm{CO}_{2} / 95 \%$ air. Mouse aortic smooth muscle cells (MASMCs) were isolated from the thoracic and upper parts of the abdominal aorta from 6- to 8-week-old male C57BL6/J mice after an intraperitoneal injection of avertin $(250 \mathrm{mg} / \mathrm{Kg})$. Briefly, the stripped aorta was isolated from the sacrificed mouse, cut into $2-\mathrm{mm}$ pieces, treated with type-II collagenase $(1 \mathrm{mg} / \mathrm{mL})$ for $1 \mathrm{~h}$ to remove endothelial cells, and washed with Dulbecco's Modified Eagle's Medium (DMEM) containing 1\% penicillin/ streptomycin solution, $1.5 \mathrm{ng} / \mathrm{mL}$ basic fibroblast growth factor, and 10\% FBS. The de-endothelialized aortic pieces were incubated in fresh complete DMEM on gelatin $(0.1 \%)$-coated culture dishes for approximately 10 days at $37^{\circ} \mathrm{C}$ in a humidified $\mathrm{CO}_{2}$ incubator with $5 \% \mathrm{CO}_{2} / 95 \%$ air. MASMCs were identified based on their 'spindle-shaped' pattern and further confirmed by double staining using PECAM-1, a specific marker of endothelial cells, and $\alpha$-smooth muscle actin ( $\alpha$-SMA), a specific marker of SMCs. All cells stained positive for $\alpha$-SMA, but not PECAM-1. For experiments, VSMCs between passages 3 and 6 were cultured in DMEM containing $0.5 \%$ FBS for $24 \mathrm{~h}$ and subjected to stimulation with TNF- $\alpha(10 \mathrm{ng} / \mathrm{mL})$. Human umbilical vein endothelial cells (HUVECs) were cultured in M199 medium supplemented with a $1 \%$ penicillin/streptomycin solution, $1.5 \mathrm{ng} / \mathrm{mL}$ basic fibroblast growth factor, and $20 \% \mathrm{FBS}$ at $37^{\circ} \mathrm{C}$ in a humidified $\mathrm{CO}_{2}$ incubator with $5 \% \mathrm{CO}_{2} / 95 \%$ air, and only passages $2-6$ were used as previously described ${ }^{21}$. 


\section{Transfection with miRNAs and siRNAs}

VSMCs and HUVECs were seeded into 6-well plates coated with poly-L-lysine at a density of $2 \times 10^{5}$ cells/well and maintained overnight in SMC medium and M199 medium containing $0.5 \% \quad$ FBS, respectively. De-endothelialized aortic rings prepared from male C57BL6/J mice were cultured in DMEM containing 0.5\% FBS for $24 \mathrm{~h}$. Cells and aortic rings were transfected with 80 and $100 \mathrm{nM}$ of siRNAs/miRNAs, respectively, in Opti-MEM reduced-serum medium using Lipofectamine RNAiMAX according to the manufacturer's instructions. Transfected cells and aortic rings were used for further experiments.

\section{Real-Time Quantitative Polymerase Chain Reaction (qRT- PCR)}

Total miRNAs from cells, tissues, and sera were isolated using an miRNeasy Mini kit or miRNeasy serum/plasma kit according to the manufacturer's instructions. The miR-155 and mRNA levels were measured as previously described ${ }^{21}$. cDNAs were synthesized from $1 \mu \mathrm{g}$ of miRNAs using a miScript II RT kit. qRT-PCR was performed to determine the miR-155 levels using a miScript SYBR Green PCR Kit as previously described ${ }^{21}$. Total mRNAs were also isolated from cells or tissues using TRIzol reagent, and the mRNA levels of the target genes were determined and quantified by qRT-PCR using their specific primers ${ }^{22}$.

\section{Western blotting}

Cells were suspended in RIPA buffer and incubated on ice for $30 \mathrm{~min}$ for complete cell lysis as previously described $^{21}$. Tissue samples were homogenized in ice-cold protein extraction buffer containing $100 \mathrm{mM}$ HEPES (pH 7.9), $10 \%$ glycerol, $5 \%$ Triton X-100, $250 \mathrm{mM} \mathrm{NaF}, 5 \mathrm{mM}$ $\mathrm{Na}_{3} \mathrm{VO}_{4}$, and Halt Protease Inhibitor Cocktail $(100 \times)$ using a BioMasher-II homogenizer (Optima, Tokyo, Japan). Cell and tissue lysates were centrifuged at $12,000 \mathrm{~g}$ at $4{ }^{\circ} \mathrm{C}$ for $10 \mathrm{~min}$, and the supernatants were collected to analyze target proteins. The lysates ( $30 \mu \mathrm{g}$ protein) were separated by SDS-polyacrylamide gel electrophoresis, and the target protein levels were determined by Western blotting using the appropriate antibodies and chemiluminescent reagents ${ }^{21}$. The relative levels of proteins were quantified by ImageJ software (NIH, Bethesda, MD, USA).

\section{Measurement of NO and cGMP}

The intracellular NO levels were measured in situ in endothelial cells using DAF-FM as previously described ${ }^{21}$. HUVECs were treated with TNF- $\alpha(10 \mathrm{ng} / \mathrm{mL})$ for $24 \mathrm{~h}$ and incubated with $5 \mu \mathrm{M}$ DAF-FM diacetate for $30 \mathrm{~min}$ in a $\mathrm{CO}_{2}$ incubator. After washing, the intracellular $\mathrm{NO}$ levels were determined from the fluorescence intensity of the DAF-FM/NO adduct by confocal microscopy at excitation/emission wavelengths of $495 / 515 \mathrm{~nm}$. The level of $\mathrm{NO}_{2}^{-}$, as a stable oxidized product of $\mathrm{NO}$, was also determined in the culture supernatants via the Griess reaction $^{23}$. Medium alone without cells was used as the negative control. Cells were collected after gentle detachment with $5 \mathrm{mM}$ EDTA, and the cell protein levels were measured according to the Lowry method. To obtain the endothelial cell-derived $\mathrm{NO}$ level, the $\mathrm{NO}_{2}{ }^{-}$level in media alone was subtracted from the total $\mathrm{NO}_{2}{ }^{-}$value. $\mathrm{NO}_{2}{ }^{-}$data were expressed as nmoles/mg of cell protein. To evaluate cGMP production, HASMCs $\left(2 \times 10^{5}\right.$ cells $)$ or mouse de-endothelialized aortic rings were transfected with or without miRNAs and stimulated with TNF- $\alpha$ ( $10 \mathrm{ng} / \mathrm{mL}$ for HASMCs and $20 \mathrm{ng} / \mathrm{mL}$ for aortic rings) for another $24 \mathrm{~h}$, followed by incubation with or without $100 \mu \mathrm{M}$ of $S$-nitroso- $N$-acetylpenicillamine (SNAP) or diethylenetriamine diazeniumdiolate (DETA/NO) for $24 \mathrm{~h}$. For co-culture experiments, HASMCs $\left(1 \times 10^{5}\right.$ cells $)$ were transfected with or without miRNAs and co-cultured with HUVECs $\left(1 \times 10^{5}\right.$ cells $)$ in 6 -well plates for $24 \mathrm{~h}$. The cGMP concentrations were measured in the aortic ring lysates and conditioned media using an ELISA kit. The protein concentration was determined by a $\mathrm{BCA}$ method in total lysates obtained from cells and aortic rings.

\section{Scratch wound healing assay}

HASMCs $\left(2 \times 10^{4}\right.$ cells/well $)$ were cultured in 6-well poly-L-lysine-coated plates using SMC medium containing $0.5 \%$ FBS overnight, transfected with miRNAs for $24 \mathrm{~h}$, and stimulated with TNF- $\alpha(10 \mathrm{ng} / \mathrm{mL})$ for $24 \mathrm{~h}$. A linear wound was applied to the center of the cell monolayer using a $200-\mu \mathrm{L}$ pipette tip and treated with or without DETA/NO $(100 \mu \mathrm{M})$ for $24 \mathrm{~h}$. Images were captured using an Olympus IX71 microscope (Olympus, Tokyo, Japan) equipped with a digital camera. The wound width was calculated as the average distance between the edges of the scratch using ImageJ software.

\section{Proliferation assay}

HASMC proliferation was determined using $\left[{ }^{3} \mathrm{H}\right]$-thymidine incorporation ${ }^{14}$. Briefly, HASMCs were seeded at a density of $2 \times 10^{4}$ cells per well in poly-L-lysine-coated 6 -well plates and cultured in SMC medium containing $0.5 \% \mathrm{FBS}$ for $24 \mathrm{~h}$. Cells were transfected with miRNAs, stimulated with TNF- $\alpha(10 \mathrm{ng} / \mathrm{mL})$ for $24 \mathrm{~h}$, and treated with or without DETA/NO $(100 \mu \mathrm{M})$ for $24 \mathrm{~h}$, followed by incubation with $1 \mu \mathrm{Ci} / \mathrm{mL}\left[{ }^{3} \mathrm{H}\right]$-thymidine for $6 \mathrm{~h}$. The level of $\left[{ }^{3} \mathrm{H}\right]$-labeled DNA was determined using a liquid scintillation counter.

\section{Measurement of sGC $\beta 1$ mRNA stability}

HASMCs were treated with or without TNF- $\alpha$ $(10 \mathrm{ng} / \mathrm{mL})$ in the presence or absence of the NF- $\mathrm{kB}$ inhibitor Bay11-7082 (Bay, $5 \mu \mathrm{M}$ ) for $12 \mathrm{~h}$. Cells were further incubated with 5,6-dichloro-1- $\beta$-D- 
ribofuranosylbenzimidazole $(40 \mu \mathrm{g} / \mathrm{mL})$ for the indicated time periods. Total mRNAs were isolated, and the sGC $\beta 1$ mRNA levels were determined by qRT-PCR.

\section{Cytoskeletal organization and morphological analysis}

HASMCs were seeded at a density of $1 \times 10^{3}$ cells/well in poly-L-lysine-coated 12-well plates and cultured in SMC medium containing $0.5 \%$ FBS for $24 \mathrm{~h}$. Cells were transfected with miRNAs and stimulated with TNF- $\alpha$ $(10 \mathrm{ng} / \mathrm{mL})$ for $24 \mathrm{~h}$, followed by treatment with or without DETA/NO $(100 \mu \mathrm{M})$ for $24 \mathrm{~h}$. The cells were fixed in $3.7 \%$ formaldehyde for $30 \mathrm{~min}$ at $25^{\circ} \mathrm{C}$, washed gently, and permeabilized with Triton X-100, followed by incubation with Alexa Fluor 488 phalloidin. Nuclei were stained with DAPI. Images were obtained using a confocal laser microscope.

\section{Mouse aortic vascular tension assay}

Because the vasodilatory mechanism can be examined using vascular tissues isolated from mice of either gender ${ }^{20}$, we assessed the effects of TNF- $\alpha$-induced miR-155 on the vascular tone in aortic vessels isolated from male mice. Briefly, 7-week-old male C57BL/6 J WT (8 animals) and miR-155 $5^{-1-}$ mice ( 5 animals) were sacrificed by an intraperitoneal injection of avertin $(250 \mathrm{mg} / \mathrm{Kg})$, and the thoracic aortic vessel was rapidly removed. The aorta was placed in ice-cold oxygenated Krebs-Ringer bicarbonate buffer and cleared of adherent connective tissues. The vessels were deendothelialized by gentle rubbing of the luminal surface and cut into $1.5-\mathrm{mm}$ rings and transfected with miRNAs $(100 \mathrm{nM})$, followed by incubation with TNF- $\alpha(20 \mathrm{ng} / \mathrm{mL})$ for $24 \mathrm{~h}$. The vessel strips were suspended between two wire stirrups $(150 \mu \mathrm{m})$ in a myograph (DMT-620, Aarhus, Denmark) containing $10 \mathrm{~mL}$ Krebs-Ringer $\left(\mathrm{pH} 7.4,37^{\circ} \mathrm{C}\right.$ ) as previously described ${ }^{14}$. The rings were passively stretched at 10 -min intervals in increments of $100 \mathrm{mg}$ to reach the optimal tone $(600 \mathrm{mg})$. The responses to the vasoconstrictor phenylephrine or $\mathrm{KCl}$ were assessed at different doses $\left(10^{-9}-10^{-5} \mathrm{M}\right.$ or $\left.0-0.1 \mathrm{M}\right)$, and the response to the vasodilator acetylcholine $\left(10^{-9}-10^{-5} \mathrm{M}\right)$ or sodium nitroprusside (SNP, $10^{-9}-10^{-5} \mathrm{M}$ ) was measured after pre-constriction with a single dose of phenylephrine $\left(10^{-5} \mathrm{M}\right)$. To further confirm that the vasorelaxation activity occurred in an NOdependent manner, vessels were treated with the sGC inhibitor $1 \mathrm{H}-[1,2,4]$ oxadiazolo[4,3-a]quinoxalin-1-one (ODQ).

\section{Statistical analysis}

Quantitative data are expressed as the mean \pm SEM of at least three separate experiments performed in triplicate. Statistical analysis was performed using GraphPad Prism 6 software (GraphPad, Inc., La Jolla, CA, USA). Data that failed the normality and equal variance tests were analyzed by the Mann-Whitney $U$ test for two groups, Kruskal-Wallis or Friedman one-way analysis of variance (ANOVA with Tukey's post-hoc test, or two-way ANOVA with the Holm-Sidak post-hoc test for two independent variables. Significance was established at a $P$ value $<0.05$.

\section{Results}

TNF- $\alpha$-induced miR-155 inhibits $s G C \beta 1$ expression

Although TNF- $\alpha$ induces miR-31 and miR-155 in an NF- $k B$-dependent manner, which inhibits eNOS expression in cultured HUVECs (Supplementary Figure 1a and b) ${ }^{14,15}$, the autonomous role of these miRNAs in the NOmediated sGC/cGMP pathway in VSMCs remains unclear. Thus, we first examined the comparative effects of these miRNAs on the eNOS/NO and sGC/cGMP pathways in cultured HUVECs as a model for studying the NO/cGMP axis because endothelial cells express both eNOS and sGC ${ }^{24}$. As anticipated, transfection of HUVECs with miR-31 and miR-155 inhibited NO production; however, the effect of miR-31 was more potent than that of miR-155, as determined by quantification of NO production using the Griess reaction and confocal microscopy (Fig. 1a and Supplementary Figure 1c). Notably, miR-31 exhibited a lower suppressive effect on cGMP production than miR-155 (Fig. 1b). These contradictory findings suggest that miR-155 has silencing activity towards sGC, which consists of the sGC 1 and sGC $\beta 1$ subunits. Thus, we examined whether TNF- $\alpha$ induced miR-155 regulates the expression of these subunits. TNF- $\alpha$ treatment decreased the protein levels of $\mathrm{sGC} \beta 1$, but not sGC $\alpha 1$, and this decrease was blocked by transfection with a miR-155 inhibitor (Fig. 1c), but not with a miR-31 inhibitor (Supplementary Figure 1b). As anticipated, transfection with a miR-155 mimic inhibited protein expression of $\mathrm{sGC} \beta 1$, but not sGC $\alpha 1$, as observed for TNF- $\alpha$ (Fig. 1c and Supplementary Figure 1d). A similar inhibitory effect on the mRNA levels of sGC $\beta 1$ was detected in HUVECs treated with TNF- $\alpha$ or the miR155 mimic (Fig. 1d). Because there were no differences in regard to the effects of the miR-155 mimic and inhibitor controls on sGC $\beta 1$ expression or cGMP synthesis (Fig. 1c, d), control miRNA was used as a common negative control for both the miR-155 mimic and inhibitor in further experiments. Collectively, these results suggest that miR-155 inhibits the eNOS/cGMP pathway by downregulating the expression of both eNOS and sGC $\beta 1$.

\section{Alterations in miR-155 and sGC $\beta 1$ levels in atherosclerotic and preeclamptic disease}

TNF- $\alpha$ is known to be a risk factor of inflammatory vascular disorders, such as atherosclerosis and preeclampsia, which are associated with VSMC dysfunc$\operatorname{tion}^{3,25}$. Therefore, we determined the expression levels of miR-155 and sGC $\beta 1$ in these disease states in humans and mice. The miR-155 levels were significantly elevated in sera from patients with atherosclerosis and in aortic vessels from $\mathrm{ApoE}^{-/-}$mice fed a HFD compared to their 

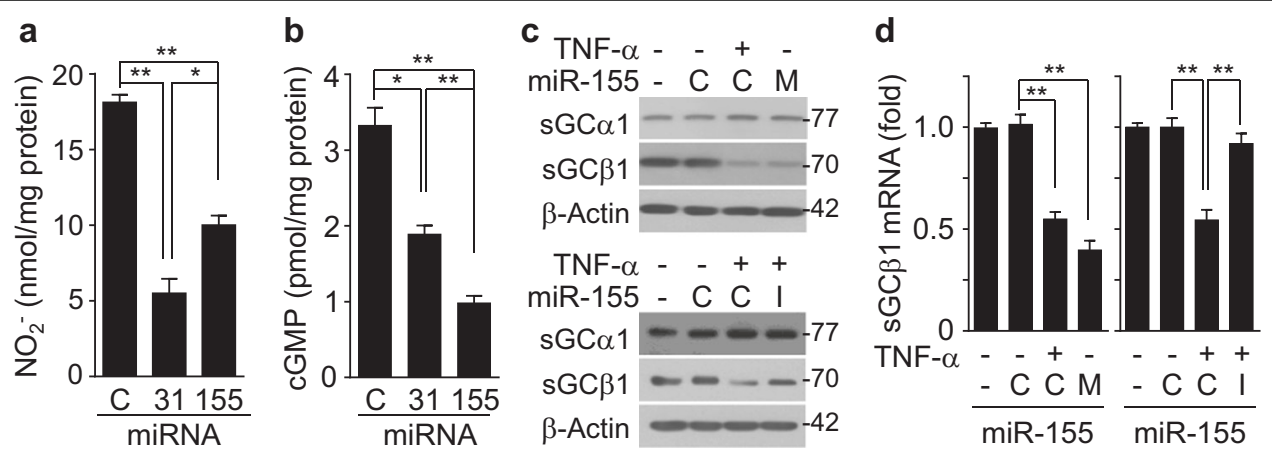

Fig. 1 Different effects of TNF- $a-$-induced miR-31 and miR-155 expression on NO and cGMP production in HUVECs. HUVECS were transfected with $80 \mathrm{nM}$ of control miRNA (C), miR-31 mimic (31), or miR-155 mimic (155) and then stimulated with or without TNF-a (10 ng/mL) for $24 \mathrm{~h}$. a The $\mathrm{NO}_{2}{ }^{-}$levels were determined in culture supernatants by the Griess reaction $(n=4)$. $\mathbf{b}$ The cellular cGMP levels were determined using a cGMP assay kit $(n=4)$. c, $\mathbf{d}$ HUVECs were transfected with $80 \mathrm{nM}$ of a specific control (C) for miR-155 mimic or miR-155 inhibitor, miR-155 mimic (M), or miR-155 inhibitor (I) and stimulated with or without TNF-a $(10 \mathrm{ng} / \mathrm{mL})$ for $24 \mathrm{~h}$. The protein and mRNA levels of sGCa1 and sGCB1 were measured by Western blotting and qRT-PCR $(n=4) .{ }^{*} P<0.05$ and ${ }^{* *} P<0.01$

control counterparts (Fig. 2a, b), whereas the sGC $\beta 1$ protein levels were decreased in aortas from HFD-fed mice (Fig. 2c). Additionally, the miR-155 levels were higher in sera and placental vessels from patients with preeclampsia than in those from healthy pregnant women (Fig. 2d), whereas the mRNA levels of sGC $\beta 1$, but not sGC $\alpha 1$, were decreased in placental vessels from preeclampsia patients compared to those in healthy controls (Fig. 2e). Therefore, miR-155 biogenesis and vascular sGC $\beta 1$ expression are inversely correlated in atherosclerotic and preeclamptic disease.

\section{TNF- $\alpha$ suppresses sGC $\beta 1$ expression via NF-KB-responsive miR-155 biogenesis}

TNF- $\alpha$ is a potent activator of NF- $\mathrm{kB}$ and is involved in the pathogenesis of various vascular disorders by impairing the NO/sGC/cGMP pathway ${ }^{26,27}$. We examined whether TNF- $\alpha$ regulates the inverse correlation between miR-155 biogenesis and sGC $\beta 1$ expression in HASMCs. Treatment of HASMCs with TNF- $\alpha$ resulted in a significant increase in miR-155 biogenesis in a timedependent manner (Fig. 3a), and this increase was blocked by treatment with the NF- $\mathrm{kB}$ inhibitor Bay11-7082 and siRNA targeting the NF-kB p65 subunit (Fig. 3b), suggesting that NF- $\mathrm{KB}$ is essential for miR-155 biogenesis $^{14,21}$. Additionally, TNF- $\alpha$ treatment inhibited the mRNA and protein levels of sGC 1 , but not sGC $\alpha 1$ (Supplementary Figure 2a-c), and this inhibition was reversed by Bay11-7082 and NF-kB p65 siRNA treatment (Fig. 3c, d). Collectively, these data suggest that TNF- $\alpha$ negatively regulates $\mathrm{sGC} \beta 1$ expression through NF-kBdependent biogenesis of miR-155.

\section{sGC $\beta 1$ is a target of miR-155}

To examine whether miR-155 inhibits sGC $\beta 1$ expression by targeting the $3^{\prime}$-UTR of its mRNA, we analyzed potential miR-155 target sites within the $3^{\prime}$-UTR of sGC $\beta 1$ mRNA using TargetScan (targetscan.org). This computational analysis revealed an apparent complementarity between the seed region of miR-155 and the $3^{\prime}$-UTR of human sGC $\beta 1 \mathrm{mRNA}$, and this sequence is relatively well conserved in other animal species, including non-human primates and mice (Supplementary Figure $3 \mathrm{a}$ and $\mathrm{b})$. To confirm this possibility, we examined the role miR-155 in sGC $\beta 1$ expression in HASMCs. Transfection with a miR-155 mimic inhibited sGC $\beta 1$ expression, and a miR-155 inhibitor reversed the TNF- $\alpha$ induced decrease in the sGC $\beta 1$ protein levels. By contrast, none of the negative controls altered the sGC $\beta 1$ protein levels (Supplementary Figure 4a and b), indicating that TNF-induced miR-155 plays an important role in sGC $\beta 1$ expression. We next examined whether miR-155 regulates the expression of human sGC $\beta 1$ by targeting its $3^{\prime}$-UTR. Treatment with TNF- $\alpha$ resulted in a decrease in the activity of a sGC $\beta 1$ mRNA 3'-UTR-based reporter, but not of its mutant reporter, and the decreased wildtype reporter activity was reversed by transfection with NF-kB p65 siRNA or a miR-155 inhibitor (Fig. 4a). Additionally, transfection of a miR-155 mimic inhibited human eNOS mRNA 3'-UTR activity, but not its mutant activity, as did treatment with TNF- $\alpha$ (Fig. 4a). Consistently, TNF- $\alpha$ or miR-155 mimic treatment inhibited the sGC $\beta 1$ mRNA and protein levels, and the inhibitory effects of TNF- $\alpha$ were mitigated by treatment with the miR-155 inhibitor (Fig. 4b, c). TNF- $\alpha$ also decreased the half-life of sGC $\beta 1$ from 16.2 to $8.5 \mathrm{~h}$, which was significantly restored to $13.8 \mathrm{~h}$ by co-treatment with the NF$\kappa \mathrm{B}$ inhibitor Bay 11-7082 (Fig. 4d), suggesting that TNF$\alpha$-induced miR-155 destabilizes sGC $\beta 1$ mRNA. We next examined the effect of miR-155 on NO-mediated cGMP synthesis. Treatment of HASMCs with TNF- $\alpha$ or a miR-155 mimic inhibited the chemical NO donor 

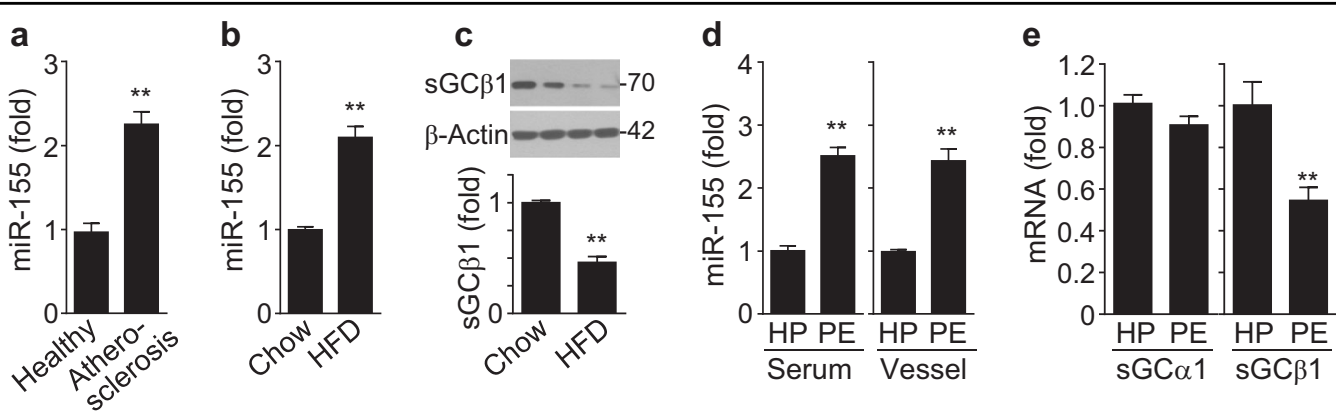

Fig. 2 MiR-155 and sGC $\beta 1$ are differentially expressed in HFD-fed ApoE ${ }^{-\prime-}$ mice and atherosclerotic and preeclamptic patients. a The miR155 levels in sera from atherosclerotic patients and healthy controls were assessed by qRT-PCR ( $n=11$ per group). $\mathbf{b}, \mathbf{c}$ The levels of miR-155 and sGC $\beta 1$ protein were determined in aortic vessels of $\mathrm{ApoE}^{-1-}$ mice fed a HFD or a chow diet by qRT-PCR and Western blotting ( $n=6$ per group). $\mathbf{d}$ The miR-155 levels in sera and placental vessels from healthy pregnant (HP) women and preeclamptic patients (PE) were determined ( $n=10$ per group). e The sGCa1 and sGC $\beta 1 \mathrm{mRNA}$ levels in placental vessels from healthy pregnant women and preeclamptic patients were analyzed by RT-PCR ( $n=10$ per group). ${ }^{*} P<0.01$
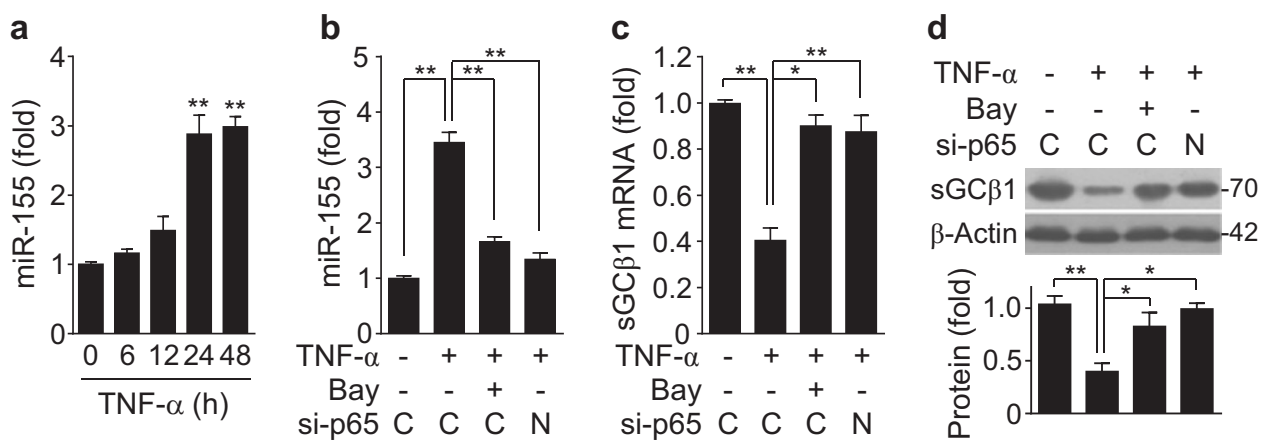

Fig. 3 TNF-a inhibits sGC $\beta 1$ expression through the biogenesis of NF-KB-responsive miR-155. a HASMCs were treated with TNF- $a(10 \mathrm{ng} / \mathrm{mL}$ ), and the miR-155 levels were determined by qRT-PCR $(n=3)$. b-d HASMCs were transfected with $80 \mathrm{nM}$ of control (C) or NF-KB p65 siRNA (N) and treated with or without TNF-a in the presence or absence of Bay11-7082 (Bay, $5 \mu \mathrm{M})$ for $24 \mathrm{~h}$. $\mathbf{b}, \mathbf{c}$ The miR-155 and sGC $\beta 1$ mRNA levels were determined by qRT-PCR $(n=6)$. d The sGC $\beta 1$ protein levels were determined by Western blotting $(n=3)$. ${ }^{*} P<0.05$ and ${ }^{* *} P<0.01$

SNAP-induced cGMP production compared to untreated control cells, and the inhibitory effect of TNF- $\alpha$ was blocked by treatment with the miR-155 inhibitor (Fig. 4e). We further determined the effect of miR-155 on cGMP production in an in vitro mimic vascular model using a co-culture system of HUVECs and HASMCs because they are able to communicate in the vasculature via eNOSdependent NO production and sGC-mediated cGMP synthesis, respectively. Co-culture of both cell types resulted in a remarkable increase in cGMP production compared to cultures of each cell type alone, and this increase was significantly decreased only when HASMCs were transfected with the miR-155 mimic (Fig. 4f). These data suggest that TNF- $\alpha$-induced miR-155 inhibits sGCdependent cGMP production by targeting the $3^{\prime}$-UTR of sGC $\beta 1$ mRNA.

\section{MiR-155 induces phenotypic switching of VSMCs}

The sGC/cGMP pathway plays an important role in maintaining the VSMC contractile phenotype and vascular relaxation. To examine whether TNF- $\alpha$-induced miR-155 regulates the expression of contractile phenotype marker genes specific to VSMCs, such as $\alpha$-smooth muscle actin $(\alpha-$ SMA), smooth muscle calponin, smooth muscle $22 \alpha$ (SM22 $\alpha$ ), and smooth muscle myosin heavy chain 11 (SMMHC11), HASMCs were treated with TNF- $\alpha$, a miR-155 mimic, or a miR-155 inhibitor, and then, the cells were treated with the NO donor DETA/NO as an in vitro model of endothelium-derived NO. Treatment with DETA/NO increased the mRNA levels of the contractile phenotype genes, and their mRNA levels were dramatically decreased by pretreatment with TNF- $\alpha$, a miR-155 mimic, or sGC $\beta 1$ siRNA to approximately $50 \%$ or less than those in untreated control cells (Fig. 5a-d). Notably, the suppressive effect of TNF- $\alpha$ on VSMC marker gene expression was reversed by treatment with the miR-155 inhibitor (Fig. 5a-d). Similar expression patterns of the marker proteins were also observed in HASMCs treated with TNF- $\alpha$, a miR-155 mimic, a miR-155 inhibitor, or sGC $\beta 1$ siRNA (Fig. 5e and Supplementary Figure $5 \mathrm{a}-\mathrm{d}$ ). These data suggest that TNF- $\alpha$ - 
a

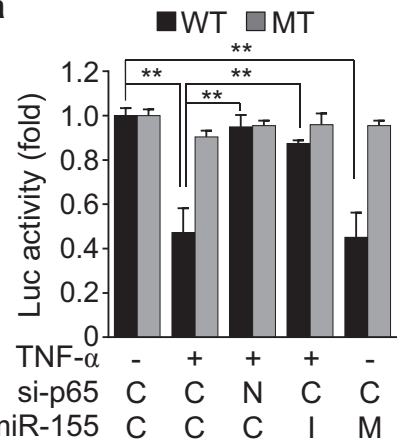

d

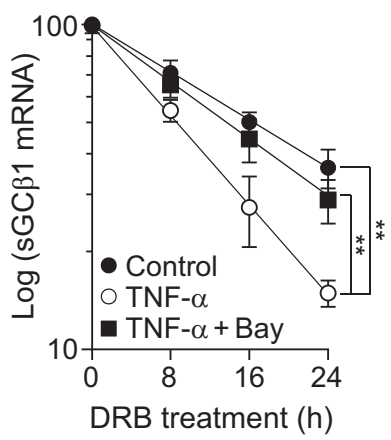

b

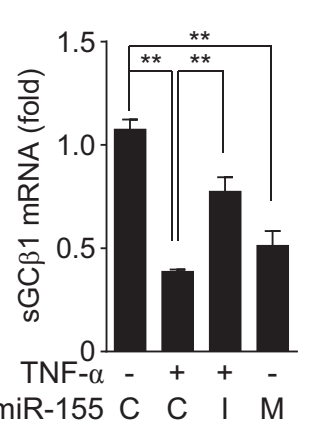

e

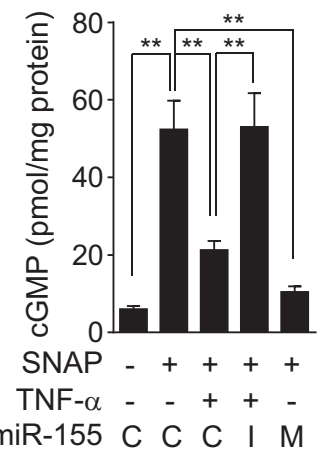

C

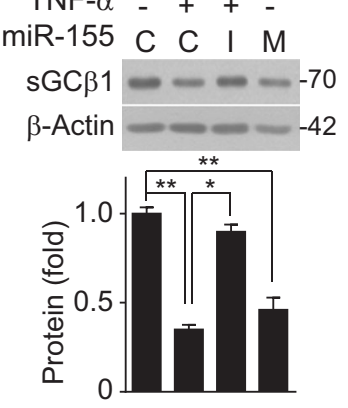

f

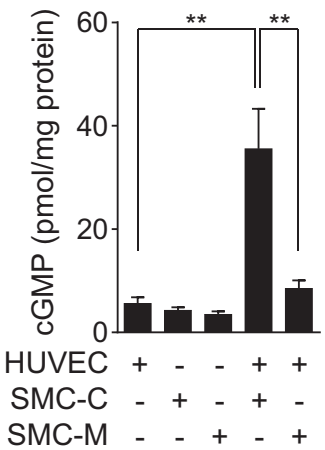

Fig. 4 MiR-155 inhibits sGC 31 expression by targeting the 3'-UTR of its transcript. a HASMCs were transfected with psiCHECK-2-sGC $\beta 1$ 3'-UTRreporter constructs [wild-type or mutant (MT)] or in combination with $80 \mathrm{nM}$ of control siRNA (C), NF-kB p65 siRNA (N), control miRNA (C), miR-155 mimic (M), or miR-155 inhibitor (I), followed by stimulation with TNF-a for $24 \mathrm{~h}$. Luciferase activity was determined using a dual-luciferase reporter assay kit $(n=3)$. b, c Transfected HASMCs were stimulated with TNF-a for $24 \mathrm{~h}$. The sGC 1 mRNA and protein levels were determined by qRT-PCR and Western blotting $(n=3)$. d Cells were stimulated with or without TNF-a in the presence or absence of Bay 1 1-7082 (Bay, $5 \mu \mathrm{M})$ for $12 \mathrm{~h}$, followed by treatment with 5,6-dichloro-1- $\beta$-D-ribofuranosylbenzimidazole $(40 \mu \mathrm{g} / \mathrm{mL})$ for the indicated time periods. The sGC $\beta 1 \mathrm{mRNA}$ levels were determined $(n=3)$. e Transfected HASMCs were stimulated with TNF-a for $24 \mathrm{~h}$, followed by further incubation with SNAP $(100 \mu M)$ for $24 \mathrm{~h}$. The cGMP levels were determined using a CGMP assay kit $(n=6)$. f HASMCs were transfected with control miRNA (SMC-C) or miR-155 mimic (SMC-M), followed by co-culture with HUVECs for $24 \mathrm{~h}$. The CGMP levels were determined using an ELISA kit $(n=4) .{ }^{*} P<0.05$ and ${ }^{* *} P<0.01$

induced miR-155 promotes VSMC phenotypic switching by impairing the sGC/cGMP pathway. We further examined the effect of TNF- $\alpha$-induced miR-155 on actin rearrangement and cell morphology in HASMCs. Treatment with TNF- $\alpha$ or a miR-155 mimic altered the elongated spindle-shaped morphology of HASMCs, resulting in a spread-out or polygonal/rhomboid cell shape with reduced cytoskeletal rearrangement in the presence of DETA/NO; the TNF- $\alpha$ induced morphological changes were effectively reversed by treatment with the miR-155 inhibitor (Supplementary Figure 6). We also examined the functional role of TNF- $\alpha$ induced miR-155 in the proliferation and migration of VSMCs, which are typical characteristics of their synthetic phenotype. TNF- $\alpha$ significantly stimulated HASMC proliferation compared to untreated control cells, whereas DETA/NO had an anti-proliferative effect (Fig. 5f). The TNF- $\alpha$-induced proliferative effect was not affected by DETA/NO, but was effectively blocked by combined treatment with a miR-155 inhibitor and DETA/NO (Fig. 5f). By contrast, the DETA/NO-induced anti-proliferation effect was suppressed by treatment with a miR-155 mimic, as seen with
TNF- $\alpha$ (Fig. 5f). Similar phenomena were also observed for the migration of HASMCs treated with a combination of DETA/NO, TNF- $\alpha$, a miR-155 mimic, and a miR-155 inhibitor (Fig. 5g and Supplementary Figure 7). Collectively, these data suggest that miR-155 promotes VSMC phenotypic switching from the contractile to the synthetic state by inhibiting the $\mathrm{NO} / \mathrm{sGC} / \mathrm{cGMP}$ pathway under inflammatory conditions.

\section{TNF-a-responsive miR-155 impairs NO-mediated vasorelaxation}

We next examined whether TNF- $\alpha$-induced miR-155 regulates NO-mediated vasorelaxation in mouse aortic rings. Treatment with TNF- $\alpha$ or a miR-155 mimic decreased the sGC $\beta 1$ mRNA and protein levels in deendothelialized mouse aortic vessels, and the effects of TNF- $\alpha$ were mitigated by treatment with the miR- 155 inhibitor (Fig. 6a). Consequently, pretreatment with TNF$\alpha$ or a miR-155 mimic significantly inhibited DETA/NOinduced cGMP production in vessel lysates and media of ex vivo cultured de-endothelialized mouse vessels, and the 
a

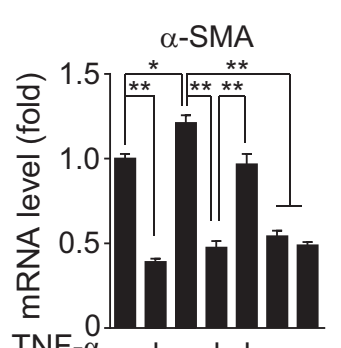

miR-155 C C C C I MC si-sGC $\beta 1$ C C C C C C S DETA/NO - - + + + ++

e

TNF- $\alpha-+-++-$ miR-155 C C C C I M C si-sGCß1 C C C C C C S $\mathrm{DETA} / \mathrm{NO}-\boldsymbol{~}_{-+++}^{+}+$

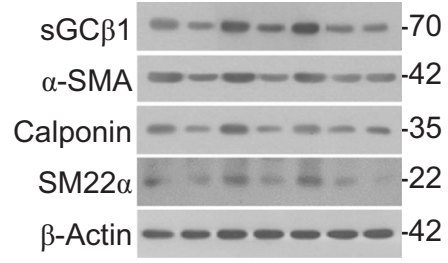

b C c

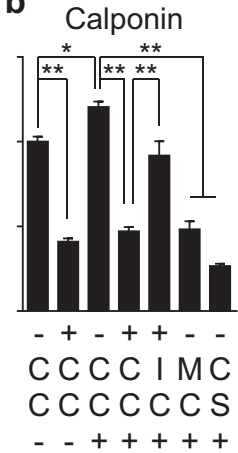

C

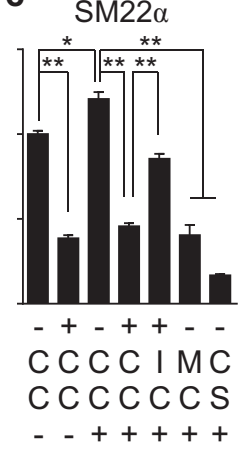

d

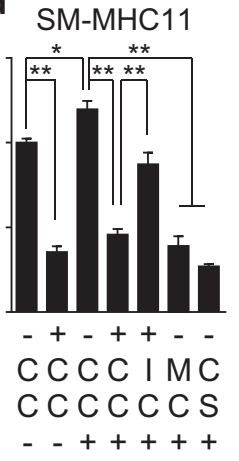

f

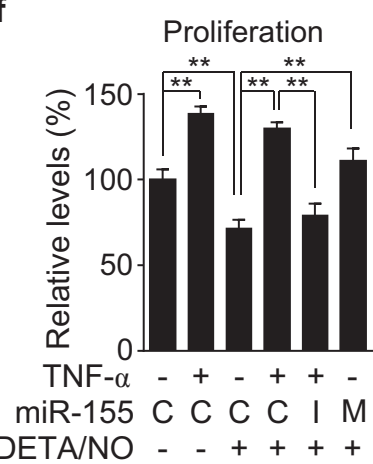

g Migration distance

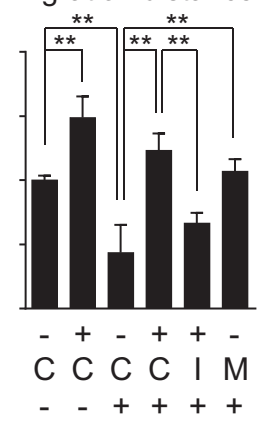

Fig. 5 TNF-a-induced miR-155 exerts VSMC phenotypic switching. HASMCs were transfected with $80 \mathrm{nM}$ of control miRNA and siRNA (C), miR155 mimic (M), miR-155 inhibitor (I), or sGCB1 siRNA (S) and stimulated with or without TNF-a (10 ng/mL) for $24 \mathrm{~h}$, followed by treatment with DETA/ NO $(100 \mu \mathrm{M})$ for another $24 \mathrm{~h}$. a-e The mRNA and protein levels of VSMC-specific marker genes were determined by qRT-PCR $(n=6)$ and Western blotting. $\mathbf{f}$ Cell proliferation was determined by a $\left[^{3} \mathrm{H}\right]$-thymidine incorporation assay $(n=3)$. $\mathbf{g}$ The migration distance was calculated as the average distance between the edges of the scratch field $(n=5)$. ${ }^{*} P<0.05$, and ${ }^{*} P<0.01$

inhibitory effect of TNF- $\alpha$ was mitigated by treatment with the miR-155 inhibitor (Fig. 6b and Supplementary Figure 8a). Treatment of de-endothelialized vessels with TNF- $\alpha$, a miR-155 mimic, or a miR-155 inhibitor did not alter the vasoconstrictor responses to phenylephrine and $\mathrm{KCl}$ (Supplementary Figure 8b and c), suggesting that VSMCs in de-endothelialized vessels maintained their normal function and integrity. In addition, these treatments did not induce a vasodilatory response of deendothelialized vessels to the endothelium-dependent vasodilator acetylcholine compared to the vasorelaxation activity of intact vessels (Supplementary Figure 8d), suggesting that TNF- $\alpha$-induced miR-155 does not affect vascular relaxation in the absence of an NO-generating source. Notably, treatment of de-endothelialized vessels with TNF- $\alpha$ or a miR-155 mimic significantly inhibited the vasorelaxant response to the chemical NO donor sodium nitroprusside (SNP), although the inhibitory effect of TNF- $\alpha$ was reversed by the miR-155 inhibitor (Fig. 6c). As expected, the vasorelaxant response to the sGC activator YC-1 was inhibited by treatment with TNF- $\alpha$ and a miR-155 mimic, and the inhibitory effect of TNF- $\alpha$ disappeared following treatment with a miR-155 inhibitor (Supplementary Figure 8e). These data suggest that TNF- $\alpha$-induced miR-155 impairs NO-dependent vasorelaxation by post-transcriptional downregulation of sGC $\beta 1$ expression in VSMCs.

\section{TNF- $a$ does not regulate NO-mediated VSMC function in miR-155 ${ }^{-/-}$aortic vessels}

We examined whether TNF- $\alpha$ regulates the sGC/cGMP axis and VSMC function in de-endothelialized aortic vessels from miR-155 ${ }^{-1-}$ mice. TNF- $\alpha$ did not regulate

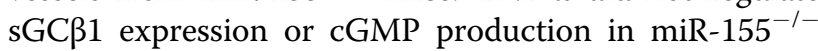
aortic vessels exposed to DETA/NO compared to those in

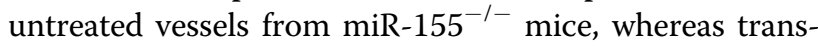
fection with a miR-155 mimic decreased sGC $\beta 1$ expression and cGMP production in miR-155 $5^{-1-}$ aortic vessels (Fig. 6d, e). Consistently, TNF- $\alpha$ did not alter the mRNA levels of VSMC-specific marker genes, such as $\alpha$-SMA, calponin, SM22 $\alpha$, and SM-MHC11, in de-endothelialized miR-155 ${ }^{-1-}$ aortic rings, while transfection of a miR-155 mimic downregulated the levels of these marker genes (Supplementary Figure 9a-d). De-endothelialized vessels from wild-type and miR- $155^{-1-}$ mice showed similar responses to $\mathrm{KCl}$-induced vasoconstriction (Supplementary Figure 10); however, treatment of de-endothelialized miR- $155^{-1-}$ vessels with a miR-155 mimic, but not 
a

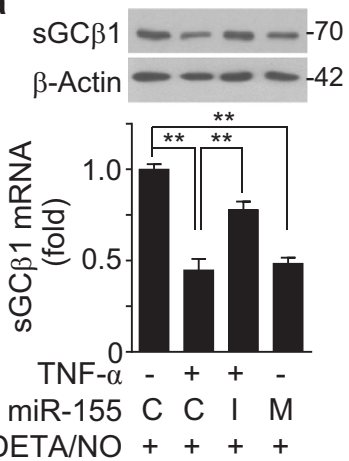

d
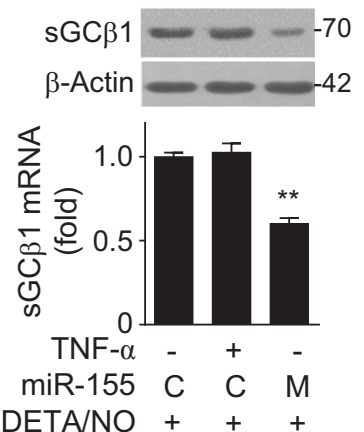

b

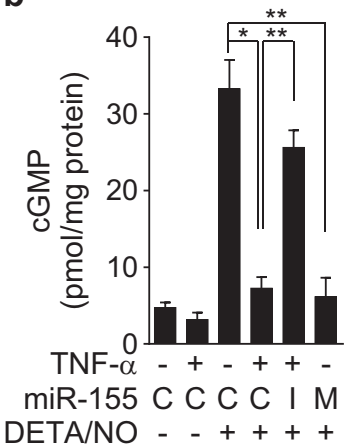

e

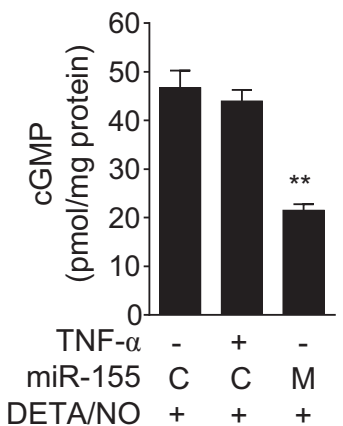

C

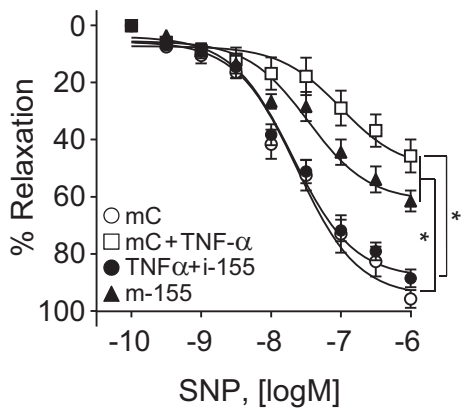

f

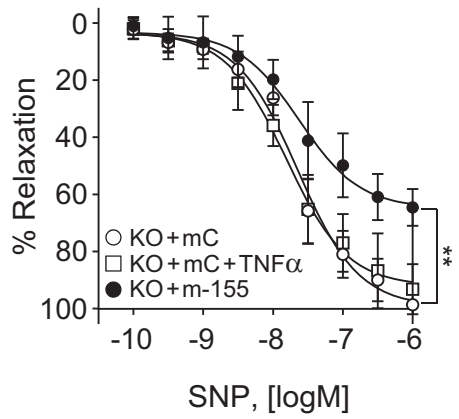

Fig. 6 MiR-155 suppresses vasorelaxation by inhibiting the sGC/cGMP pathway. a Mouse de-endothelialized aortic rings were transfected with $100 \mathrm{nM}$ of control miRNA (C), miR-155 mimic (M), or miR-155 inhibitor (I), followed by treatment with or without TNF-a (20 ng/mL) for $24 \mathrm{~h}$. The sGC $\beta 1$ mRNA and protein levels were determined by qRT-PCR $(n=3)$ and Western blotting. $\mathbf{b}$ De-endothelialized aortic rings were transfected with miR-155 mimic and miR-155 inhibitor and stimulated with or without TNF-a for $24 \mathrm{~h}$, followed by treatment with DETA/NO for another $24 \mathrm{~h}$. The cGMP levels were determined in vessel lysates using a cGMP assay kit $(n=3)$. c De-endothelialized aortic rings were transfected with control miRNA, miR-155 mimic (m-155), or miR-155 inhibitor (i-155), followed by treatment with TNF-a for $24 \mathrm{~h}$. The cumulative vascular relaxation response of the aortic rings to SNP was measured by myography $(n=8)$. $\mathbf{d}-\mathbf{f}$ De-endothelialized aortic rings from miR-155 ${ }^{-1-}(\mathrm{KO})$ mice were transfected with $100 \mathrm{nM}$ of control miRNA (C, mC) or miR-155 mimic (M, m-155) and stimulated with or without TNF-a for $24 \mathrm{~h}$, followed by treatment with DETA/NO $(100 \mu \mathrm{M})$ for another $24 \mathrm{~h}$. $\mathbf{d}$ The $\mathrm{SGC} \beta 1$ mRNA levels were determined $(n=5)$. e The cGMP levels were determined using a cGMP assay kit $(n=5)$. f The relaxation response of de-endothelialized miR-155-/- $(\mathrm{KO})$ aortic rings to SNP was measured by myography $(n=5)$. ${ }^{*} P<0.05$ and ${ }^{* *} P<0.01$

TNF- $\alpha$, inhibited SNP-induced vasodilation (Fig. 6f). These data suggest that miR-155 inhibits the sGC/cGMP pathway, which is essential for maintaining the VSMC phenotype and vasodilation.

\section{Discussion}

VSMCs are highly specialized cells that have a contractile capability in blood vessels and, in concert with endothelial cells, are essential for the maintenance of vascular function. Through constriction and relaxation, they control the luminal diameter, which enables blood vessels to maintain a normal blood pressure. VSMCs possess phenotypic plasticity that allows for rapid adaptation to fluctuating environmental cues, such as growth factors, mechanical influences, and various inflammatory mediators. These conditions stimulate phenotypic changes of VSMCs from a quiescent contractile phenotype to an active synthetic state, which results in intimal hyperplasia and impaired contractility. Although inflammatory responses stimulate VSMC phenotypic modulation, the underlying mechanism is largely unknown.

The present study shows that TNF- $\alpha$ stimulates NF-kBdependent biogenesis of miR-155, the levels of which were substantially upregulated in both mouse atherosclerotic arteries and samples from patients with atherosclerosis and preeclampsia. The miR-155 levels were inversely correlated with sGC $\beta 1$ expression in atherosclerotic mice and preeclamptic patients. We also found that TNF- $\alpha$ and miR-155 mimic treatment induced VSMC phenotypic switching and mitigated $\mathrm{NO}$-induced vasodilation by suppressing sGC-dependent cGMP production. However, treatment with a miR-155 mimic, but not TNF- $\alpha$, dysregulated VSMC function in miR-155 $5^{-1-}$ aortic vessels. Therefore, these results suggest that NF-кB-responsive miR-155 is a novel negative regulator of VSMC function (Supplementary Figure 11), which plays important roles in the induction of intimal hyperplasia and hypertension associated with atherosclerosis and preeclampsia. 
Inflammatory cytokines, such as TNF- $\alpha$ and IL- 6 that are known to be potent activators of NF- $\mathrm{kB}$, are risk factors for vascular disorders, including atherosclerosis, preeclampsia, and hypertension ${ }^{28-30}$, which suggests that inflammatory cytokines stimulate phenotypic modulation of VSMCs by downregulating the expression of their contractile biomarker genes, likely through activation of $\mathrm{NF}-\mathrm{KB}^{31}$. In fact, inhibition of NF- $\mathrm{KB}$ activation using a pharmacological inhibitor prevents lipopolysaccharideinduced VSMC proliferation and atherosclerosis lesions in $\mathrm{ApoE}^{-1-}$ mice ${ }^{32}$. Additionally, SMC-selective inhibition of NF- $\mathrm{kB}$ has been shown to attenuate SMC phenotypic switching and neointima formation following vascular injury ${ }^{31}$. These data suggest that NF- $k B$ plays an important role in repressing VSMC differentiation marker genes. Although NF-kB stimulates transcriptional expression of numerous genes, our data demonstrated that TNF- $\alpha$-induced activation of NF- $\kappa B$ inhibited sGC $\beta 1$ expression through the biogenesis of miR-155, which directly targets the $3^{\prime}-$ UTR of its transcript. Therefore, NF- $k B$-responsive miR-155 is a negative regulator of the sGC/cGMP pathway and is responsible for maintaining the VSMC contractile phenotype.

In the vasculature, eNOS-derived NO in the endothelium diffuses to the underlying vascular smooth muscle where it acts to maintain vascular tone and VSMC plasticity by stimulating the sGC/cGMP pathway, with subsequent activation of cGMP-dependent protein kinase (PKG). sGC expression has been shown to be downregulated in spontaneously hypertensive rats and angiotensin II-induced hypertensive mice ${ }^{33-35}$, and whole-body or SMC-specific deletion of sGC $\beta 1$ causes hypertension in mice ${ }^{36,37}$. These observations indicate that impairments of the sGC/cGMP pathway contribute to the pathogenesis of hypertension. In addition, pharmacological activation of sGC has been shown to exert an anti-atherosclerotic effect in $\mathrm{ApoE}^{-1-}$ mice ${ }^{38}$, as well as inhibit VSMC proliferation and arterial neointima formation in a rat model of experimental balloon injury ${ }^{39}$. However, there are contradictory data showing that genetic deletion of sGC 1 , another subunit of dimeric sGC, in mice prevents the phenotypic switching and proliferation of VSMCs ${ }^{40}$. Based on these observations, it appears that the sGC/ cGMP pathway contributes to VSMC dysfunction associated with intimal growth and hypertension. Here, we also found that miR-155 induced VSMC phenotypic switching and inhibited NO-mediated vasorelaxation by downregulating sGC $\beta 1$ expression. These results suggest that NF-kB-responsive miR-155 disrupts the maintenance of VSMC function, leading to intimal proliferation and vasoconstriction.

Among the many different intracellular messengers, cGMP is largely generated in SMCs by NO-mediated activation of sGC. cGMP exerts its anti-proliferative and vasodilatory effects through activation of $\mathrm{PKG}^{41,42}$. Activated PKG phosphorylates the vasodilator-stimulated phosphoprotein at Ser239 ${ }^{42}$, resulting in actin polymerization and maintenance of the VSMC contractile phenotype. In addition, the cGMP/PKG pathway induces vasorelaxation via activation of myosin light chain phosphatase in VSMCs ${ }^{43}$. Indeed, genetic deletion of PKG in mice results in impaired vasorelaxation and hypertension $^{44}$, whereas expression of a constitutively active PKG reduces the neointima formation associated with the phenotypic modulation of VSMCs following vascular injury ${ }^{45}$. Thus, the sGC/cGMP/PKG pathway is a crucial signaling component in VSMC-dependent vascular function and homeostasis. Our data show that NF-kB-induced miR-155 downregulates sGC $\beta 1$ expression in VSMCs, leading to inhibition of the NO/cGMP pathway and VSMC dysfunction under inflammatory conditions.

The sGC/cGMP axis is activated in the vasculature by endothelium-derived NO production. Thus, eNOSdeficient mice induce neointimal proliferation after vascular injury and spontaneous hypertension ${ }^{5,6,46}$, indicating that eNOS-derived NO plays an important role in preventing VSMC proliferation (hyperplastic remodeling) and hypertension. Although eNOS is constitutively expressed, recent studies have reported that this gene is negatively regulated by the NF- $\mathrm{kB}$-dependent biogenesis of miR-155 in humans, but not in mice, leading to endothelial dysfunction and vasoconstriction ${ }^{14,15}$. In addition, our previous data have shown that miR-155 also downregulates PKG1 expression ${ }^{47}$. Moreover, in the present study, we demonstrate that miR-155 potentially inhibits sGC $\beta 1$ expression in both humans and mice. These findings suggest that TNF- $\alpha$-induced miR-155 is crucially involved in vascular dysfunction by targeting the mRNA transcripts of eNOS, sGC $\beta 1$, and PKG1 in humans. These data indicate that NF- $\kappa B$ plays a key role in the pathogenesis of preeclampsia, atherosclerosis, and other inflammatory vascular disorders through the biogenesis of miR-155.

Although at first glance atherosclerosis and preeclampsia seem to be caused by independent risk factors, both syndromes can, in fact, be caused by many common risk factors ${ }^{48}$, including inflammatory cytokines and oxidative stress, and the underlying mechanism(s) associated with preeclampsia is linked to a large contribution from cardiovascular risk factors that are present prior to gestational hypertension ${ }^{49}$. Indeed, women with preeclampsia develop atherosclerosis-like lesions in the arteries of their uterine wall during pregnancy and have a two-fold higher risk for subsequent cardiovascular disease, suggesting shared underlying mechanisms in the pathogenesis of both diseases $^{50}$. There are common clinical and cellular features of inflammation, NF- $\mathrm{kB}$ activation, and endothelial and VSMC 
dysfunction in the pathogenesis of atherosclerosis and preeclampsia ${ }^{4,14,28,35,48}$. Several studies have shown that NFkB-responsive miR-155 causes dysfunction in both endothelial cells and VSMCs by downregulating eNOS expres$\operatorname{sion}^{14,15,51}$. Additionally, the present study showed that TNF- $\alpha$-induced miR-155 promoted VSMC proliferation and inhibited vasorelaxation in an NF- $\mathrm{kB}$-dependent manner by downregulating the expression of $s G C B 1$. These events are crucial for the pathogenesis of atherosclerosis and preeclampsia, both of which are associated with impaired VSMC dysfunction ${ }^{49}$.

Taken together, the present study demonstrates that TNF- $\alpha$-induced miR-155 inhibits sGC $\beta 1$ expression in an $\mathrm{NF}-\mathrm{kB}$-dependent manner by targeting its transcript, resulting in inhibition of the sGC/cGMP pathway. The dysfunctional sGC/cGMP axis results in phenotypic alterations of VSMCs and impairs vascular relaxation, both of which are associated with various vascular diseases. These findings offer a possible mechanistic link between NF- $\mathrm{kB}$ and VSMC dysfunction through miR155-mediated downregulation of sGC $\beta 1$ during the development of atherosclerosis and preeclampsia. In combination with our previous studies ${ }^{14,15,47}$, the present data support that miR-155, a negative regulator of eNOS, sGC $\beta 1$, and PKG1 in the vasculature, is a common therapeutic target for the development of treatments for atherosclerosis and preeclampsia.

\section{Acknowledgements}

This work was supported by National Research Foundation of Korea (NRF) grants funded by the Korea Government (2016M3A9B6903103 and 2017R1A2B3004565).

\section{Author details}

'Departments of Molecular and Cellular Biochemistry, Kangwon National University School of Medicine, Chuncheon, Gangwon-do 24341, South Korea. ${ }^{2}$ Departments of Obstetrics and Gynecology, Kangwon National University School of Medicine, Chuncheon, Gangwon-do 24341, South Korea. ${ }^{3}$ Departments of Neurobiology, Kangwon National University School of Medicine, Chuncheon, Gangwon-do 24341, South Korea. ${ }^{4}$ Department of Biology, College of Natural Sciences, Kangwon National University, Chuncheon, Gangwon-do 24341, South Korea. ${ }^{5}$ Department of Systems Immunology, College of Biomedical Science, Kangwon National University, Chuncheon, Gangwon-do 24341, South Korea. ${ }^{6}$ Department of Biochemistry, College of Life Science and Biotechnology, Yonsei University, Seoul 03722, South Korea

\section{Conflict of interest}

The authors declare that they have no conflict of interest.

\section{Publisher's note}

Springer Nature remains neutral with regard to jurisdictional claims in published maps and institutional affiliations.

Supplementary information accompanies this paper at https://doi.org/ 10.1038/s12276-019-0212-8.

Received: 18 September 2018 Revised: 12 November 2018 Accepted: 19 November 2018.

Published online: 15 February 2019

\section{References}

1. Vanhoutte, P. M., Zhao, Y., Xu, A. \& Leung, S. W. Thirty years of saying NO: sources, fate, actions, and misfortunes of the endothelium-derived vasodilator mediator. Circ. Res. 119, 375-396 (2016)

2. Gomez, D. \& Owens, G. K. Smooth muscle cell phenotypic switching in atherosclerosis. Cardiovasc. Res. 95, 156-164 (2012).

3. Hering, L. et al. Trophoblasts reduce the vascular smooth muscle cell proatherogenic response. Hypertension 51, 554-559 (2008).

4. Lincoln, T. M., Dey, N. B., Boerth, N. J., Cornwell, T. L. \& Soff, G. A. Nitric oxidecyclic GMP pathway regulates vascular smooth muscle cell phenotypic modulation: implications in vascular diseases. Acta Physiol. Scand. 164, 507-515 (1998).

5. Moroi, M. et al. Interaction of genetic deficiency of endothelial nitric oxide, gender, and pregnancy in vascular response to injury in mice. J. Clin. Invest. 101, 1225-1232 (1998).

6. Huang, P. L. et al. Hypertension in mice lacking the gene for endothelial nitric oxide synthase. Nature 377, 239-242 (1995).

7. Ruetten, H., Zabel, U., Linz, W. \& Schmidt, H. H. Downregulation of soluble guanylyl cyclase in young and aging spontaneously hypertensive rats. Circ. Res. 85, 534-541 (1999).

8. Pedraza, C. E., Baltrons, M. A., Heneka, T. M. \& García, A. Interleukin-1 $\beta$ and lipopolysaccharide decrease soluble guanylyl cyclase in cells of the CNS: NOindependent destabilization of protein and NO-dependent decrease of mRNA. J. Neuroimmunol. 144, 80-90 (2003).

9. Bartel, D. P. MicroRNA: target recognition and regulatory functions. Cell 136, 215-233 (2009)

10. Yang, F. et al. miRNA-22 is a novel mediator of vascular smooth muscle cell phenotypic modulation and neointima formation. Circulation 137, 1824-1841 (2018).

11. Torella, D. et al. MicroRNA-133 controls vascular smooth muscle cell phenotypic switch in vitro and vascular remodeling in vivo. Circ. Res. 109, 880-893 (2011).

12. Liu, H. et al. Upregulation of microRNA-214 contributes to the development of vascular remodeling in hypoxia-induced pulmonary hypertension via targeting CCNL2. Sci. Rep. 6, 24661 (2016).

13. Chistiakov, D. A., Orekhov, A. N. \& Bobryshev, Y. V. Chemokines and relevant microRNAs in the atherogenic process. Mini Rev. Med. Chem. 18,597-608 (2018).

14. Kim, J. et al. Aspirin prevents TNF-a-induced endothelial cell dysfunction by regulating the NF-KB-dependent miR-155/eNOS pathway: Role of a miR-155/ eNOS axis in preeclampsia. Free Radic. Biol. Med. 104, 185-198 (2017).

15. Choi, S. et al. Carbon monoxide prevents TNF-a-induced eNOS downregulation by inhibiting NF-kB-responsive miR-155-5p biogenesis. Exp. Mol. Med. 49, e403 (2017).

16. Eis, P. S. et al. Accumulation of miR-155 and BIC RNA in human B cell lymphomas. Proc. Natl Acad. Sci. USA 102, 3627-3632 (2005).

17. Nazari-Jahantigh, M. et al. MicroRNA-155 promotes atherosclerosis by repressing Bcl6 in macrophages. J. Clin. Invest. 122, 4190-4202 (2012).

18. Mann, M. et al. An NF-kB-microRNA regulatory network tunes macrophage inflammatory responses. Nat. Commun. 8, 851 (2017).

19. Zheng, B. et al. Exosome-mediated miR-155 transfer from smooth muscle cells to endothelial cells induces endothelial injury and promotes atherosclerosis. Mol. Ther. 25, 1279-1294 (2017).

20. Robinet, P. et al. Consideration of sex differences in design and reporting of experimental arterial pathology studies-statement from ATVB council. Arterioscler. Thromb. Vasc. Biol. 38, 292-303 (2018).

21. Lee, K. S. et al. Functional role of NF-KB in expression of human endothelial nitric oxide synthase. Biochem. Biophys. Res. Commun. 448, 101-107 (2014).

22. Yang, L. et al. Lactate promotes synthetic phenotype in vascular smooth muscle cells. Circ. Res. 121, 1251-1262 (2017).

23. Matsushita, H. et al. eNOS activity is reduced in senescent human endothelial cells: Preservation by hTERT immortalization. Circ. Res. 89, 793-798 (2001).

24. Fernhoff, N. B., Derbyshire, E. R. \& Marletta, M. A. A nitric oxide/cysteine interaction mediates the activation of soluble guanylate cyclase. Proc. Natl Acad. Sci. USA 106(51), 21602-21607 (2009).

25. Davis-Dusenbery, B. N., Wu, C. \& Hata, A. Micro-managing vascular smooth muscle cell differentiation and phenotypic modulation. Arterioscler. Thromb. Vasc. Biol. 31, 2370-2377 (2011).

26. Vaughan, J. E. \& Walsh, S. W. Activation of NF-KB in placentas of women with preeclampsia. Hypertens. Pregnancy 31, 243-251 (2012). 
27. de Winther, M. P., Kanters, E., Kraal, G. \& Hofker, M. H. Nuclear factor kB signaling in atherogenesis. Arterioscler. Thromb. Vasc. Biol. 25, 904-914 (2005).

28. Shaw, J. et al. Inflammatory processes are specifically enhanced in endothelial cells by placental-derived TNF-a: Implications in preeclampsia (PE). Placenta 43, 1-8 (2016).

29. Naya, M. et al. Plasma interleukin-6 and tumor necrosis factor-alpha can predict coronary endothelial dysfunction in hypertensive patients. Hypertens. Res. 30, 541-548 (2007).

30. Brand, K. et al. Activated transcription factor nuclear factor- $\mathrm{KB}$ is present in the atherosclerotic lesion. J. Clin. Invest. 97, 1715-1722 (1996).

31. Yoshida, T., Yamashita, M., Horimai, C. \& Hayashi, M. Smooth muscle-selective inhibition of nuclear factor-kB attenuates smooth muscle phenotypic switching and neointima formation following vascular injury. J. Am. Heart Assoc. 2, e000230 (2013).

32. Mallavia, B. et al. Peptide inhibitor of NF-kB translocation ameliorates experimental atherosclerosis. Am. J. Pathol. 182, 1910-1921 (2013).

33. Bauersachs, J. et al. Vasodilator dysfunction in aged spontaneously hypertensive rats: changes in NO synthase III and soluble guanylyl cyclase expression, and in superoxide anion production. Cardiovasc. Res. 37, 772-779 (1998)

34. Ruetten, H., Zabel, U., Linz, W. \& Schmidt, H. H. Downregulation of soluble guanylyl cyclase in young and aging spontaneously hypertensive rats. Circ. Res. 85, 534-541 (1999).

35. Rippe, C. et al. Hypertension reduces soluble guanylyl cyclase expression in the mouse aorta via the Notch signaling pathway. Sci. Rep. 7, 1334 (2017).

36. Friebe, A., Mergia, E., Dangel, O., Lange, A. \& Koesling, D. Fatal gastrointestinal obstruction and hypertension in mice lacking nitric oxide-sensitive guanylyl cyclase. Proc. Natl Acad. Sci. USA 104, 7699-7704 (2007).

37. Groneberg, D. et al. Smooth muscle-specific deletion of nitric oxide-sensitive guanylyl cyclase is sufficient to induce hypertension in mice. Circulation 121, 401-409 (2010).

38. Tsou, C. Y. et al. Activation of soluble guanylyl cyclase prevents foam cell formation and atherosclerosis. Acta Physiol. 2014, 799-810 (2014).

39. Tulis, D. A. et al. YC-1-mediated vascular protection through inhibition of smooth muscle cell proliferation and platelet function. Biochem. Biophys. Res. Commun. 291, 1014-1021 (2002).
40. Segura-Puimedon, $M$. et al. Proatherosclerotic effect of the a1-subunit of soluble guanylyl cyclase by promoting smooth muscle phenotypic switching. Am. J. Pathol. 186, 2220-2231 (2016).

41. Mulsch, A. et al. Effects of in vivo nitroglycerin treatment on activity and expression of the guanylyl cyclase and CGMP-dependent protein kinase and their downstream target vasodilator-stimulated phosphoprotein in aorta. Circulation 103, 2188-2194 (2001).

42. Chen, L. et al. Vasodilator-stimulated phosphoprotein regulates proliferation and growth inhibition by nitric oxide in vascular smooth muscle cells. Arterioscler. Thromb. Vasc. Biol. 24, 1403-1408 (2004).

43. Munzel, T. et al. Physiology and pathophysiology of vascular signaling controlled by cyclic guanosine $3^{\prime}, 5^{\prime}$-cycylic monophosphate-dependent protein kinase. Circulation 108, 2172-2183 (2003).

44. Pfeifer, A. et al. Defective smooth muscle regulation in CGMP kinase I-deficient mice. EMBO J. 17, 3045-3051 (1998).

45. Sinnaeve, P. et al. Overexpression of a constitutively active protein kinase G mutant reduces neointima formation and in-stent restenosis. Circulation $\mathbf{1 0 5}$, 2911-2916 (2002).

46. Rudic, R. D. et al. Direct evidence for the importance of endotheliumderived nitric oxide in vascular remodeling. J. Clin. Invest. 101, 731-736 (1998).

47. Choi, S. et al. TNF-a elicits phenotypic and functional alterations of vascular smooth muscle cells by miR-155-5p-dependent downregulation of cGMPdependent kinase 1. J. Biol. Chem. 293, 14812-14822 (2018).

48. Hermes, W., Van Kesteren, F. \& De Groot, C. J. Preeclampsia and cardiovascular risk. Minerva Ginecol. 64, 281-292 (2012).

49. Romundstad, P. R., Magnussen, E. B., Smith, G. D. \& Vatten, L. J. Hypertension in pregnancy and later cardiovascular risk: common antecedents? Circulation 122, 579-584 (2010).

50. Intapad, S. \& Alexander, B. T. Future cardiovascular risk: Interpreting the importance of increased blood pressure during pregnancy. Circulation 127, 668-669 (2013).

51. Zhang, J., Zhao, F., Yu, X., Lu, X. \& Zheng, G. MicroRNA-155 modulates the proliferation of vascular smooth muscle cells by targeting endothelial nitric oxide synthase. Int. J. Mol. Med. 35, 1708-1714 (2015). 